The out-of-plane vibrations are notable for their greatly diminished frequencies in the excited state as compared with the ground-state. The reductions, shown below, clearly mirror that weakening of the plane-retaining forces due to the unsaturation electrons, which results from the lifting of one such electron into a higher orbital : in terms of Bell's representation of the force system, the hydrogen force constant becomes approximately halved, and the carbon force constant reduced to about one third of its value, in consequence of the exeitation.

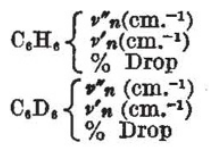

$\begin{array}{rrr}671 & 703 & \mathbf{9 8 5} \\ 513 & 364 & \sim \mathbf{7 7 4} \\ 24 & 48 & \sim 21 \\ 496 & 601 & 827 \\ \mathbf{3 8 2} & 307 & \sim 637 \\ \mathbf{2 3} & 49 & \sim 23\end{array}$

$\begin{array}{rr}849 & 405 \\ 586 & 242 \\ 31 & 40 \\ 662 & 352 \\ 454 & 208 \\ 31 & 41\end{array}$

970

708

27

793

26

No general discussion of the in-plane vibrations can be included in this note; but it may be remarked that an assignment already suggested of the frequencies $2565 \mathrm{~cm}^{-1}$ of $\mathrm{C}_{6} \mathrm{H}_{6}$ and $1821 \mathrm{~cm}^{-1}$ (or a weaker neighbouring frequency) of $\mathrm{C}_{6} \mathrm{D}_{6}$ to the upper state $A_{1 g}(\mathrm{H})$ vibration is shown by the product theorem to be at least partly incorrect, since, in combination with the known frequencies, $923 \mathrm{~cm}^{-1}$ of $\mathrm{C}_{6} \mathrm{H}_{8}$ and $879 \mathrm{~cm}^{-1}$ of $\mathrm{C}_{6} \mathrm{D}_{6}$, of the upper state $A_{1 g^{\prime}}(\mathrm{C})$ vibration, they lead to a quite unacceptable value of the upper state $A_{1 g}$ product ratio.

A fuller consideration of all these matters will be published elsewhere.

Sir William Ramsay and

C. K. Ingord.

Frandesoa M. Leeke.

Ralph Forster Laboratories,

University College, London. Oct. 19 .

${ }^{1}$ J. Chem. Phys., 5, 669 (1937); 7, 207 (1939).

Ingold and Wilson, J. Chem. Soc., 941 (1936). Wilson, J. Chem. Soc., 1210 (1936). Radle and Beck, J. Chem. Phys., 8, 507 (1940). Sponer, J. Chem. Phys., 705 (1940).

$\checkmark$. Chem. Soc. (in the press).

-Trans. Faraday Soc., 41, 293 (1945).

\section{Lattice Distortions and Shear in Aluminium Single Crystals}

DEFORMATION experiments have been carried out with aluminium single crystals by means of a specially constructed apparatus (Bausch apparatus ${ }^{1}$ ), which approximates a pure shear (the applied stress being parallel to the glide plane (111) and to the glide direction [110] ). Fig. 1 is a reproduction of a photograph of a sheared erystal. The experiments have shown that even such a deformation process causes an asterism of the Laue interference spots, pointing to the presence of locally curved lattice regions, the direction of curvature being perpendicular to the direction of gliding.

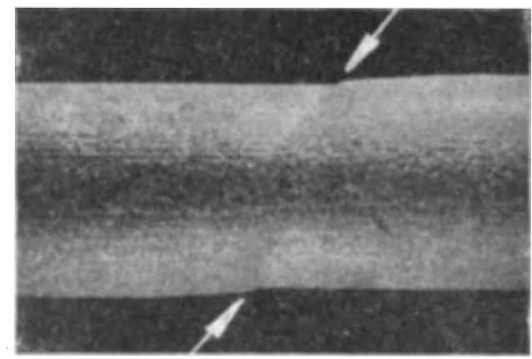

Aluminium single crystal after a shear $0.4 \times 10$.
It is suggested that the absence of asterism shown by naphthalene erystals subjected to the same process, as observed by Kochendörfer ${ }^{2}$, is due to the fact that in this crystal the number of active glide planes is much larger than in aluminium (the width of the glide lamellæ being thus correspondingly smaller), so that the number of arrested dislocations along each individual active glide plane is much smaller and thus the resulting curvature much weaker.

From our experiments we infer that shear hardening is not necessarily accompanied by a curvature of the glide planes of sufficient magnitude to give rise to Laue asterism. It may be caused both by a large number of 'individually' arrested dislocations (causing only slight curvatures of the lattice) and by a small number of 'groups' of arrested dislocations (causing much larger curvatures of the glide planes).

Crystals were also sheared in directions differing from the combination (111) [110], known from extension and compression experiments. In all these cases a Laue asterism, similar in character to that mentioned above, was observed. Moreover, the shear stress-shear curves coincided for all the orientations investigated, at least within the limits of accuracy attained. They resemble closely the stress-strain curves obtained by Taylor ${ }^{3}$ and by Karnop and Sachs ${ }^{4}$ in extension and compression experiments with aluminium single crystals.

On the ground of the experimental evidence, arguments can be given in favour of the view that in aluminium gliding may be forced along lattice planes and directions differing from the combination (111) [110], for values of shear stress which do not vary considerably for different glide combinations.

The experimental fact that no broadening of the Debye-Scherrer interference lines is observed in heavily deformed (rolled or drawn) aluminium may be connected with this behaviour.

Details will be given in a fortheoming paper in Rec. Trav. Chim. Pays-Bas.

W. G. Burgers.

Laboratory for Physical Chemistry, F. J. LeBBINK.

Technical University, Delft. Aug. 22.

${ }^{1}$ Bausch, K., Z. Phys., 93, 479 (1935).

Kochendörfer, A., "Plastische Eigenschaften von Kristallen und metallischen Werkstoffen" (Berlin, 1941), 11 et seq.

a Taylor, G. I., Proc. Roy. Soc., A, 116, 39 (1927).

- Karnop, R., and Sachs, G., Z. Phys., 41, 116 (1927).

\section{Solar Radiations in the 4-6 Metre Radio Wave-Length Band}

THE solar radiation spectrum does not normally extend into the 5-metre wave-length region with sufficient intensity to be detectable on radio receiving equipments in commercial or Service use. It is now possible to disclose that, on one occasion during the War, Army equipments observed solar radiations of the order of $10^{5}$ times the power expected from the sun, assuming that the sun behaves as a perfect black-body radiator at a temperature of $6,000^{\circ} \mathrm{K}$.

This abnormally high intensity of solar radiation occurred on February 27 and 28, 1942, when Army radar receiving equipments, working at various wavelengths in the 4-6 metre band, noticed strong directional radiations similar in character to the random fluctuations of internal receiver noise (thermal and valve noise). The radiation was first detected in the afternoon on February 26, 1942, and was almost 